\title{
Micro-thermal analysis and evolved gas analysis
}

\author{
Duncan M. Price ${ }^{\mathrm{a},{ }^{*}}$, Mike Reading ${ }^{\mathrm{a}}$, Trevor J. Lever ${ }^{\mathrm{b}}$, \\ Azzedine Hammiche ${ }^{\mathrm{c}}$, Hubert M. Pollock \\ a IPTME, Loughborough University, Loughborough, Leics LE11 3TU, UK \\ ${ }^{\mathrm{b}}$ TA Instruments Ltd., Europe House, Bilton Centre, Cleave Road, Leatherhead, Surrey KT22 7UQ, UK \\ ${ }^{\mathrm{c}}$ School of Physics, Lancaster University, Lancaster LA1 4YB, UK \\ Received 27 September 1999; accepted 28 February 2000
}

\begin{abstract}
Micro-thermal analysis employs an active heated tip in a scanning probe microscope. This allows topographic and thermal imaging of surfaces to be carried out and permits localised thermal analysis of selected areas of material. In order to provide a means for spatially resolved chemical characterization, a method of trapping the gases that are evolved when the thermal probe is used to pyrolyze the surface has been developed. The trapped gases can then be thermally desorbed and passed into a GC-MS system for separation and identification. With this system it is possible to ablate a small $(<10 \mu \mathrm{m} \times 10 \mu \mathrm{m})$ area of a sample (or a domain, feature or contaminant) and elucidate its composition. This paper presents initial results for a homogeneous polymer (poly(methyl methacrylate)) — and a heterogeneous polymer blend (polystyrene/poly( $\alpha$-methyl styrene)). (C) 2001 Elsevier Science B.V. All rights reserved.
\end{abstract}

Keywords: Scanning probe thermal microscopy; Localized thermal analysis; Localized pyrolysis; Evolved gas analysis

\section{Introduction}

Micro-thermal analysis (micro-TA) combines the imaging capabilities of atomic force microscopy with the physical characterization capabilities of thermal analysis $[1,2]$. Specimens may be visualized by means of their topography and ability to conduct heat. The images so obtained can then be used as a means of selecting positions on the sample to carry out the spatially resolved equivalents of the "macro-TA" techniques such as TMA and modulated temperature DSC. With some knowledge of the components in the sample and their likely thermal responses (e.g. melting point, softening temperature, etc.) it is possible to use the results from such experiments to elucidate the

\footnotetext{
${ }^{*}$ Corresponding author. Fax: +44-1509-223332.

E-mail address: d.m.price@lboro.ac.uk (D.M. Price).
}

nature and distribution of different phases within the bulk. Where the chemistry of the sample is unknown however, one may be forced to resort to the more traditional methods of surface analysis capable of providing localized compositional information (such as X-ray photoelectron spectroscopy (XPS) or secondary ion mass spectrometry (SIMS)) [3]. However, XPS and SIMS are often inconvenient techniques to employ since they require the sample to be analyzed under high vacuum. The chemical information that they produce can be limited - especially in the case of complex mixtures.

In the "macro-world" there is a long history of using analytical pyrolysis methods to probe the structure of polymers [4]. Samples are simply heated so as to decompose them into small fragments which are then analyzed by mass spectrometry (MS) or capillary gas chromatography-mass spectrometry (GC-MS). A 
number of systems have been described whereby the sample is heated in a thermobalance and the evolved gases trapped and analyzed [5]. In the realms of microTA it is easy to use the resistively heated probe as a means of locally ablating material from the surface. We have now combined this into a system whereby the evolved gases are captured and then analyzed by GC-MS. Furthermore, the ability to perform localized pyrolysis experiments within a small volume of material enhances the value of the technique.

\section{Experimental}

Measurements were carried out on a TA Instruments 2990 Micro-Thermal Analyzer based on a ThermoMicroscopes Explorer Scanning Probe Microscope with the addition of an active thermal probe and associated electronics. Imaging and localised thermal analysis can be carried out in the usual way. For pyrolysis experiments the probe is placed in contact with the region of interest and rapidly heated to $600^{\circ} \mathrm{C}$. The evolved gases are trapped in a specially designed tube packed with a suitable sorbent such as Tenax or Carbopak. The tube comes to a fine point which is placed immediately adjacent to the heated thermal probe using a micro-manipulator. As the probe is heated, a syringe is used to draw gas through the tube which is then placed in a thermal desorbtion unit (TA Instruments Evolved Gas Collector) for analysis of the trapped volatiles by GC-MS (Hewlett-Packard 6890 Gas Chromatograph with HP5973 Mass Selective Detector). The GC was fitted with an HP-5 MS capillary column $(30 \mathrm{~m} \times 0.25 \mathrm{~mm}$ i.d., $10 \mu \mathrm{m}$ d.f. $)$ and held at $40^{\circ} \mathrm{C}$ for $5 \mathrm{~min}$ following desorbtion and then heated at $15^{\circ} \mathrm{C} \mathrm{min}^{-1}$ to $250^{\circ} \mathrm{C}$. Mass spectra

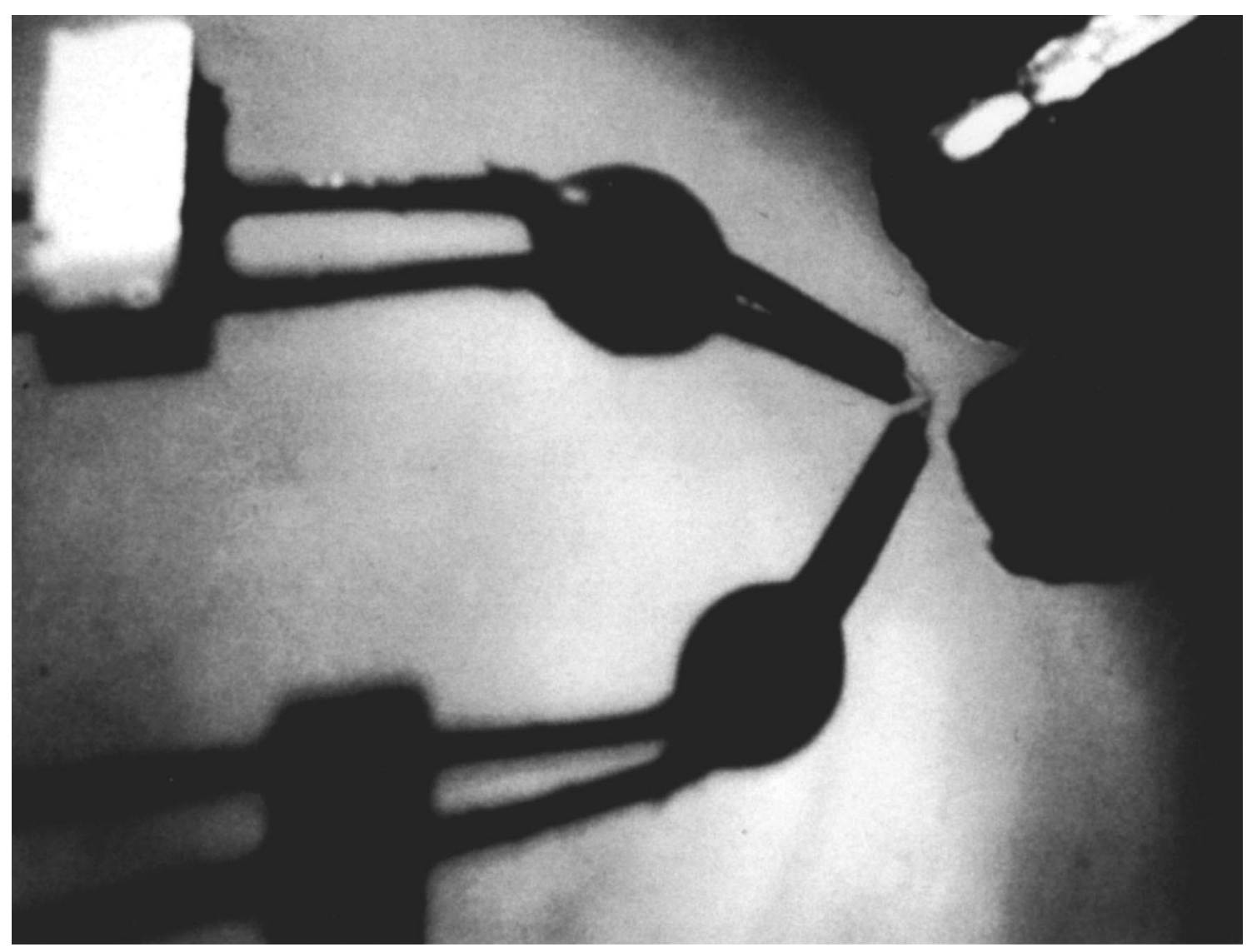

Fig. 1. Thermal probe and end of adsorbent tube. 


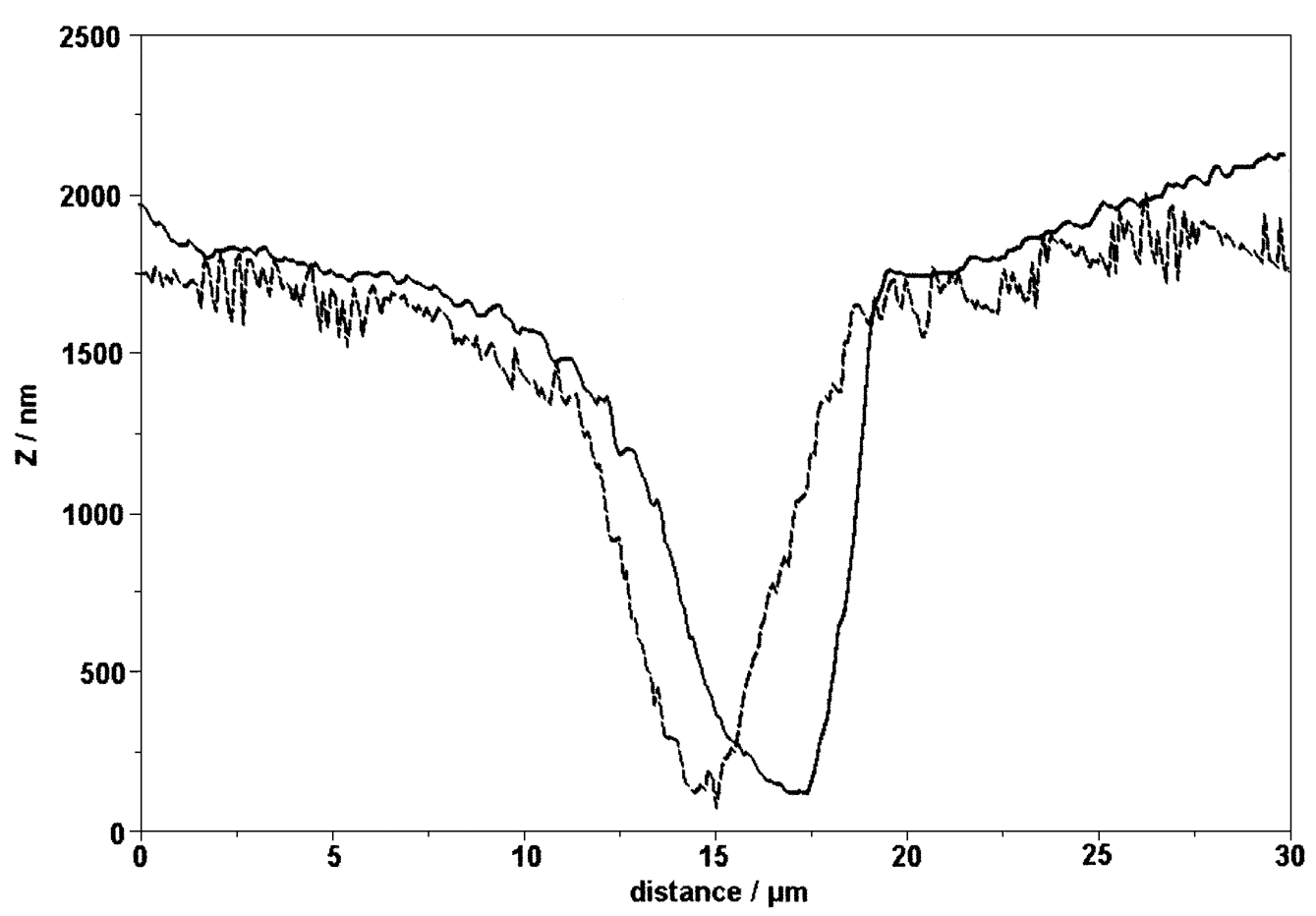

Fig. 2. Three dimensional perspective view of a pyrolysis crater on a poly(methyl methacrylate) sheet.

$(\mathrm{m} / z$ 45-350) were acquired every $0.5 \mathrm{~s}$. A blank desorbtion run was carried out before and after each experiment to confirm the cleanliness of the detection system. Fig. 1 shows a view of the thermal probe and end of the sorbent tube as seen by the operator via a CCD camera attached to the microscope.

Modulated-temperature DSC measurements were carried out on a TA Instruments DSC 2920 at an underlying heating rate of $3^{\circ} \mathrm{C} \mathrm{min}^{-1}$, amplitude $0.6^{\circ} \mathrm{C}$ and period $60 \mathrm{~s}$. The instrument was calibrated according to the manufacturer's instructions using indium and sapphire.

\section{Results and discussion}

An example of a pyrolysis crater on a poly(methyl methacrylate) sheet (ICI Perspex) obtained using the thermal probe is shown in Fig. 2. Line profiles horizontally and vertically across the image indicate that the pit is $6 \mu \mathrm{m}$ in diameter and $1.7 \mu \mathrm{m}$ deep (Fig. 3). Not all of this volume was pyrolized since some of the material flows away from the probe on heating. Fig. 4 shows the total ion chromatogram obtained from the material trapped in the sorbent tube. A mass spectrum taken from peak at a retention time of $2.43 \mathrm{~min}$ corresponds to methyl methacrylate monomer generated by unzipping of the polymer (Fig. 5). This mode of decomposition is quite common for many additional polymers [6].

A scanning thermal micrograph of a sample of polystyrene (PS - Polysciences, $M_{\mathrm{w}} \approx 125-250$ $\times 10^{3} \mathrm{~g} \mathrm{~mol}^{-1}$ ) pressed sheet is shown in Fig. 6 . The raw material was deliberately contaminated with some pellets of low molecular weight $\operatorname{poly}(\alpha$-methyl styrene) (PaMS - Polysciences, $M_{\mathrm{w}} \approx 790 \mathrm{~g} \mathrm{~mol}^{-1}$ ) and then moulded at $125^{\circ} \mathrm{C}$ under $25 \mathrm{kPa}$ pressure for a few minutes so as to preserve discrete domains of each component. Modulated-temperature DSC results for the specimen are shown in Fig. 7. There is little evidence to show the presence of PaMS since its glass rubber transition is broad $\left(50-60^{\circ} \mathrm{C}\right)$ and low intensity - particularly in this case, where the PaMS is the minority component.

The sample was then mounted under the microscope and scanned using the thermal probe at $50^{\circ} \mathrm{C}$. 


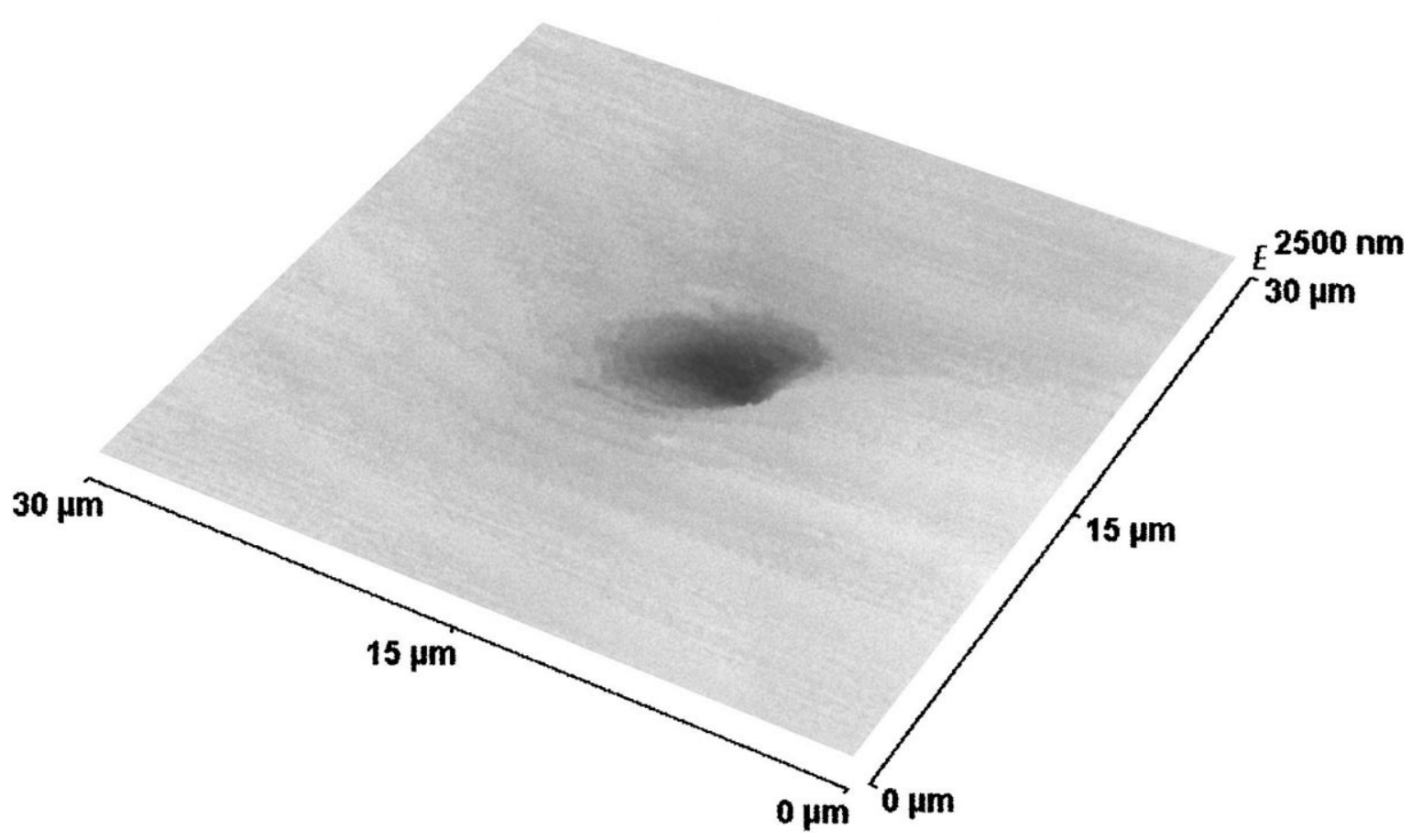

Fig. 3. Line profiles horizontally (-) and vertically (- -) across the crater in Fig. 2.

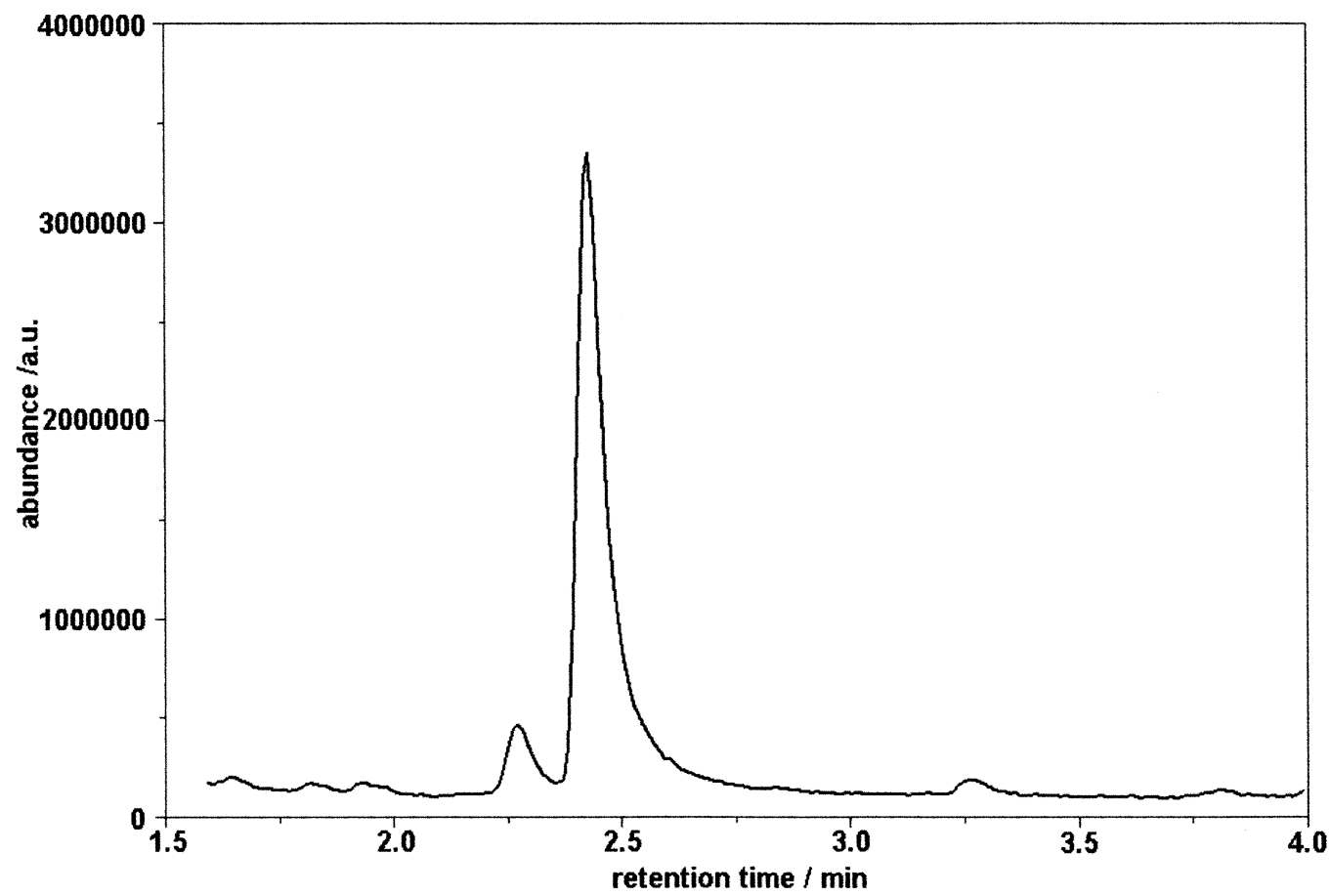

Fig. 4. Total ion chromatogram of the pyrolysis products from the crater in Fig. 2. 


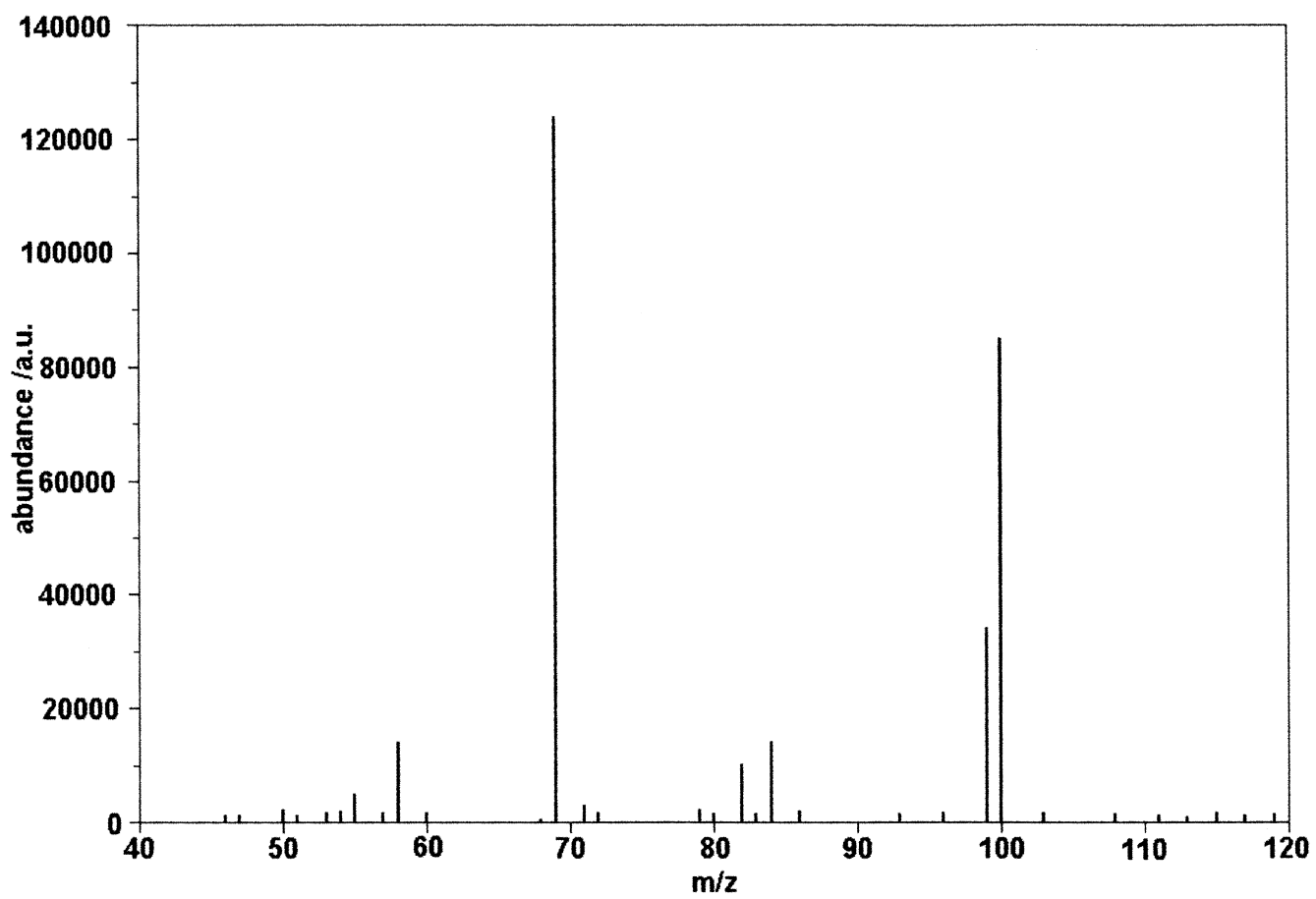

Fig. 5. Mass spectrum of methyl methacrylate monomer at retention time of 2.43 min in Fig. 4.

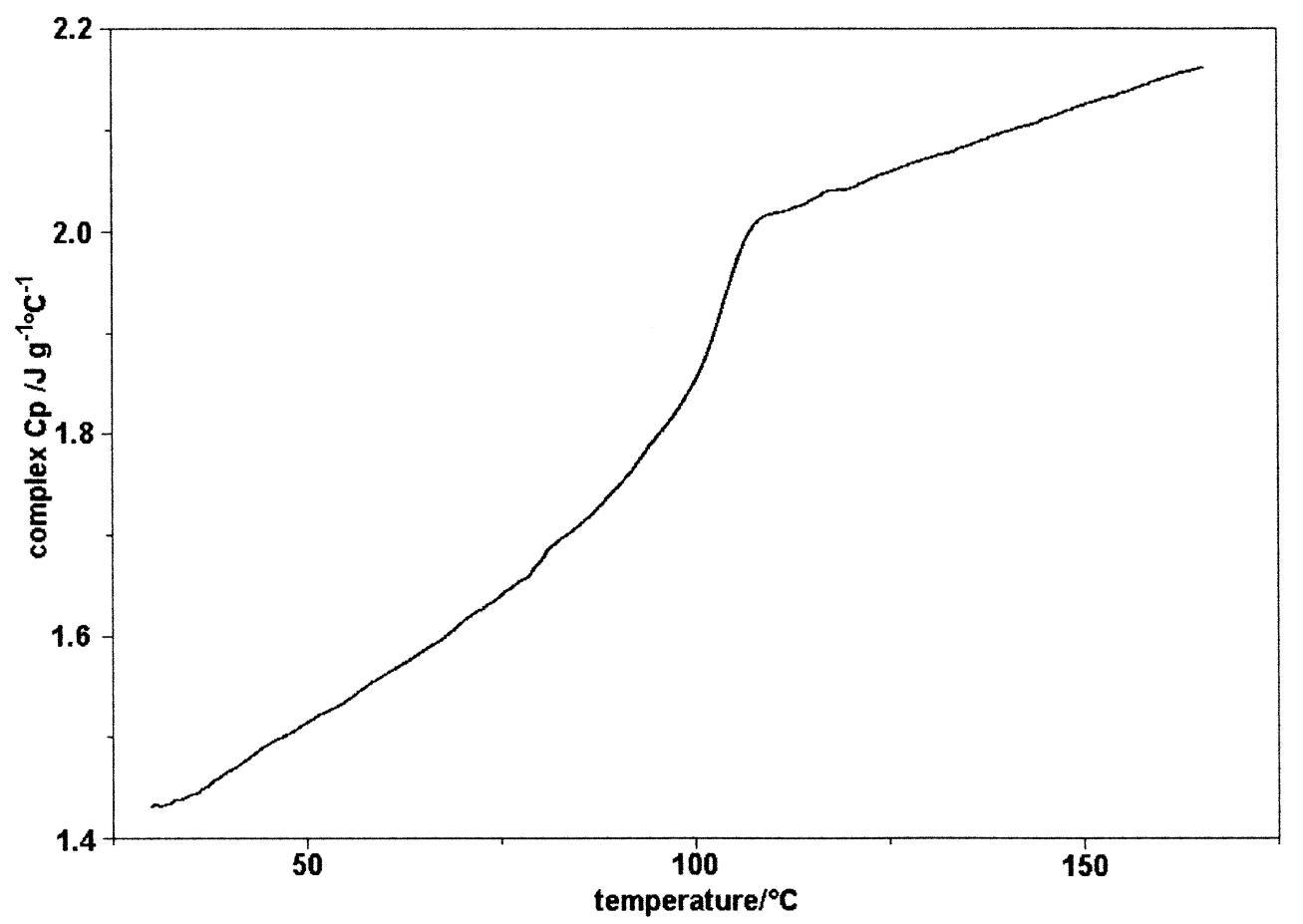

Fig. 6. Thermal image of PS sheet containing PaMS (see text). 


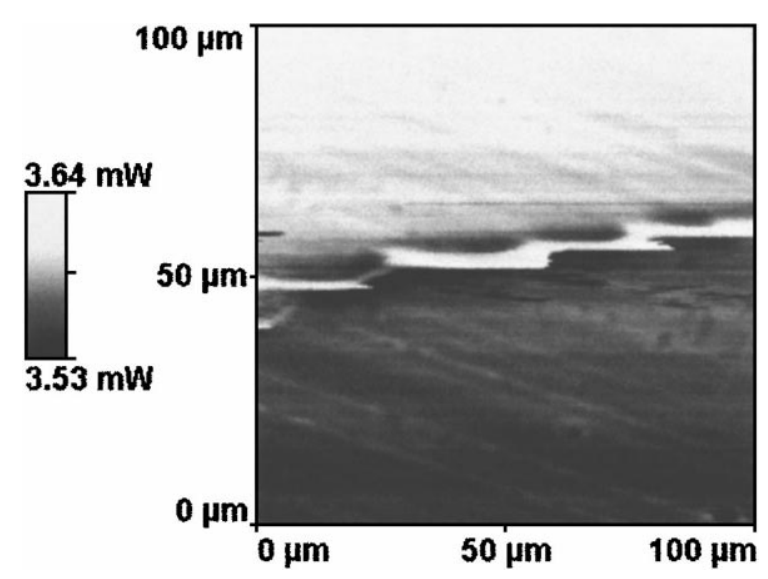

Fig. 7. Modulated temperature DSC scan of PS sheet containing PaMS.

The thermal image contrast of a $100 \mu \mathrm{m} \times 100 \mu \mathrm{m}$ region shown in Fig. 6 suggests that the two phases are present. Micro-TMA measurements indicate that the material present in the lower thermal conductivity region (bottom) has a softening temperature consistent with the raw PaMS whereas the material in the higher thermal conductivity region is probably PS (Fig. 8).

Pyrolysis experiments on areas from the top and bottom of the image confirm that there are differences in composition between the two locations. PS and PaMS both decompose to yield monomer $(\mathrm{m} / \mathrm{z}, 104$ and 118 for their molecular ions, respectively) (Fig. 9). Single ion chromatograms monitoring these masses are shown in Fig. 10. These show that the region at the top of the image is primarily composed of PS and that the region at the bottom of the image comprises mainly PaMS. There is evidently some cross-contamination of the two polymers (and there is also some contribution to the ion of $\mathrm{m} / \mathrm{z}, 104$ from PaMS due to the $9 \%{ }^{13} \mathrm{C}$ abundance of $\mathrm{m} / z 103\left(\mathrm{C}_{8} \mathrm{H}_{7}{ }^{+}\right)$derived from methyl loss from the monomer molecular ion [7]). Mullens et al. [8] has used online thermogravimetry-(FTIR) evolved gas analysis and offline thermal desorbtion GC-MS to study a similar system. In the present study, we are not only able to detect the existence of impurities, but also determine where they are located.

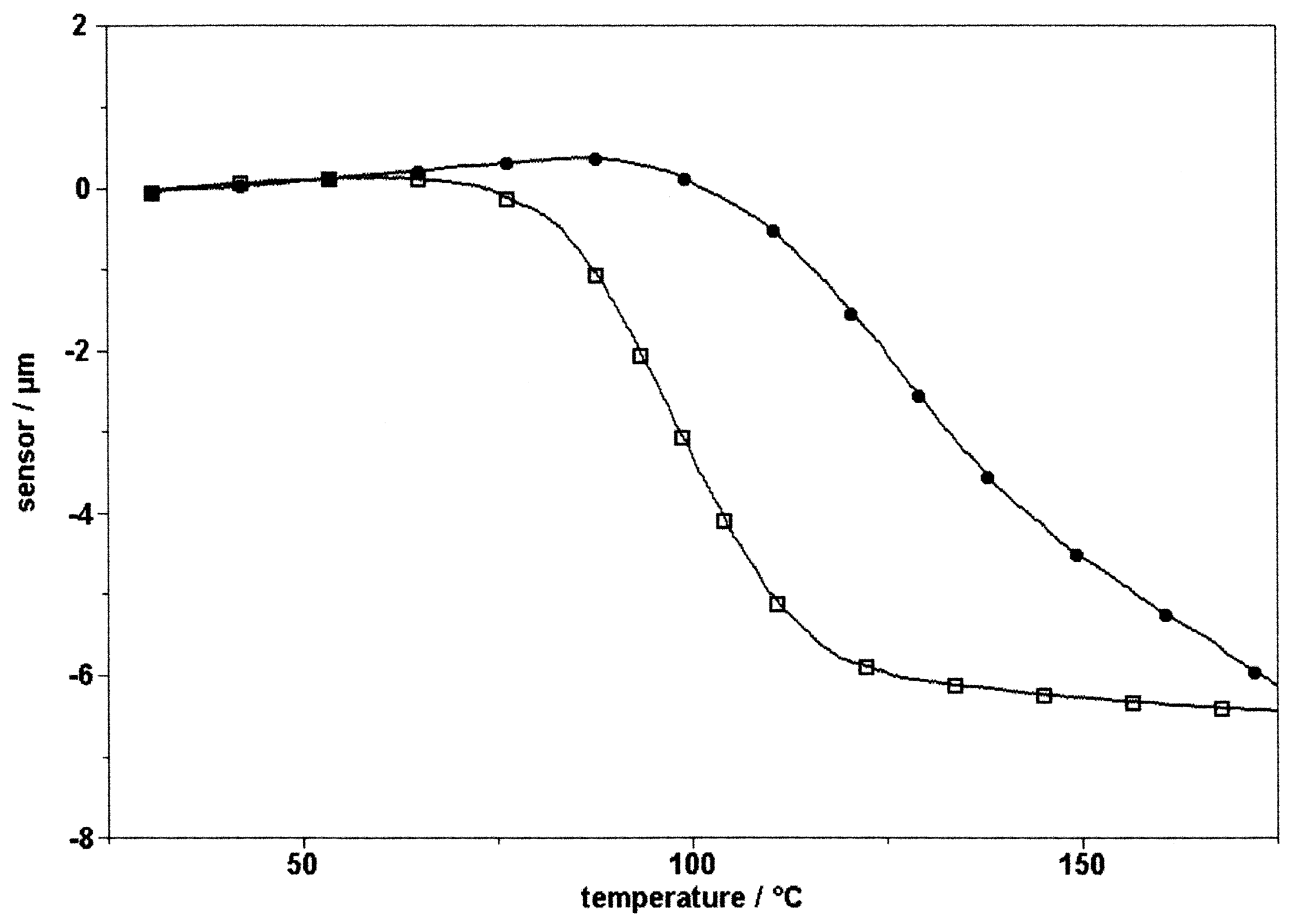

Fig. 8. Micro-TMA curves for locations at top left $((\bullet) 25 \mathrm{~m} \times 75 \mathrm{~m})$ and bottom right $((\square) 75 \mu \mathrm{m} \times 25 \mu \mathrm{m})$ of the image in Fig. 6 . 


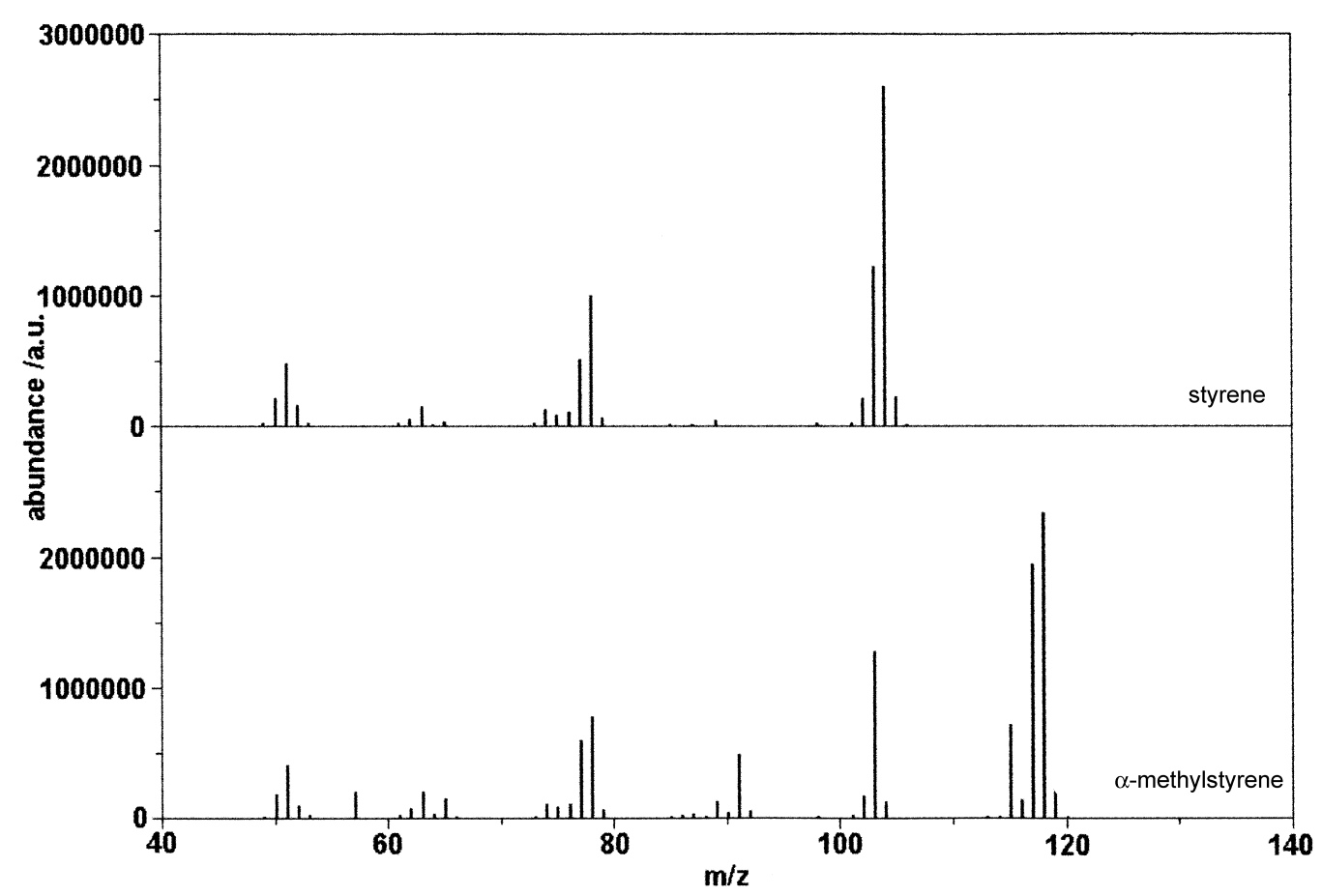

Fig. 9. Mass spectra of styrene (top) and $\alpha$-methyl styrene (bottom) - typical decomposition products of PS and PaMS.

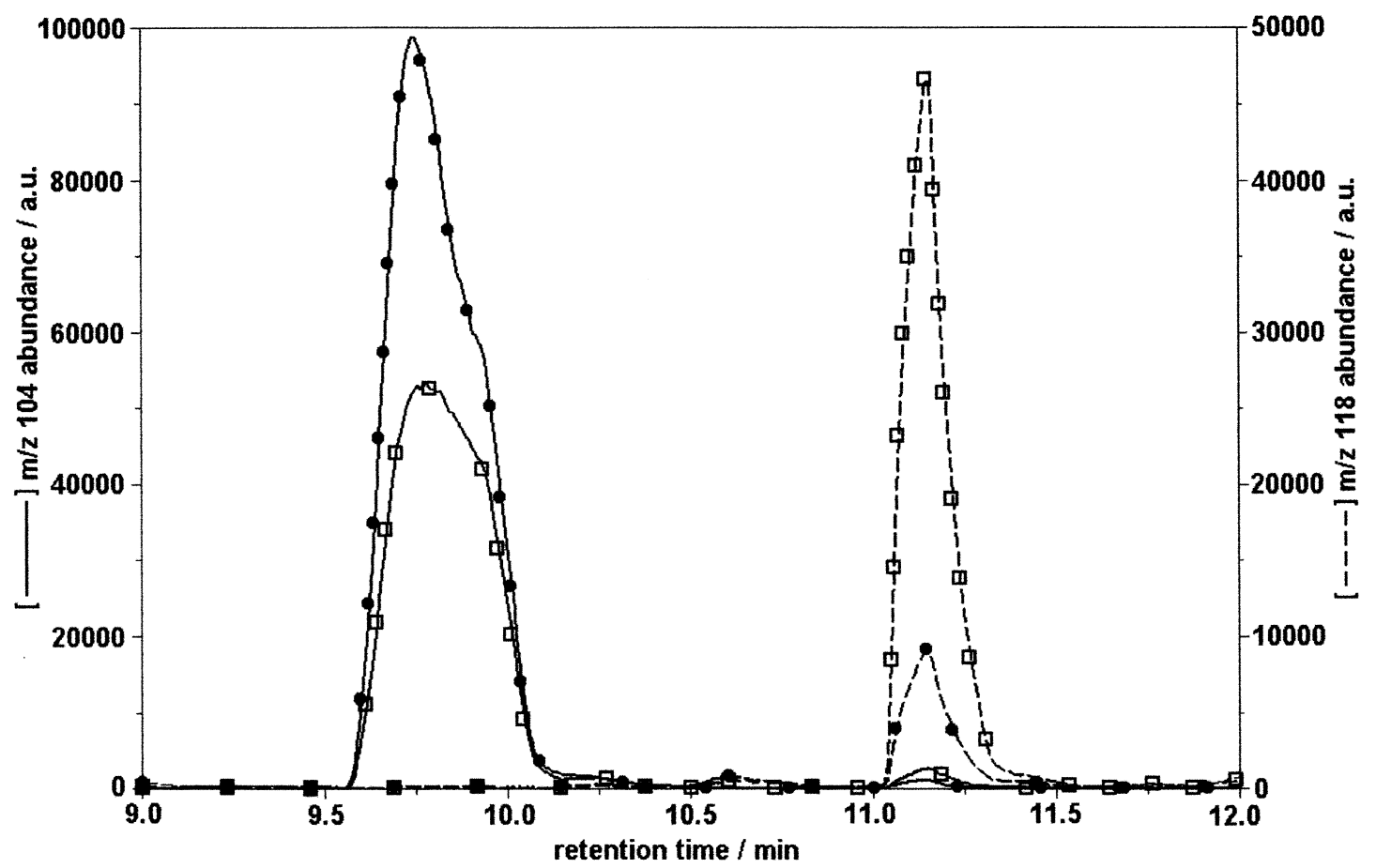

Fig. 10. Single ion chromatograms for styrene $(-, m / z, 104)$ and $\alpha$-methyl styrene $(--, m / z, 118)$ from similar locations as Fig. $8((\bullet)$ $11.5 \mu \mathrm{m} \times 95.5 \mu \mathrm{m} ;(\square) 95.5 \mu \mathrm{m} \times 7.5 \mu \mathrm{m})$. 
Hammiche et al. [9] have shown that it is possible to use the thermal probe to detect localized temperature changes on the surface of samples brought about by absorbtion of infrared radiation. In this way, photothermal near-field infrared spectra can be obtained with a resolution better than that obtainable with conventional infrared microscopy. Although not yet commercially available, we hope to incorporate this feature into the same instrument and thus be able to perform spatially resolved chemical analysis by pyrolysis-GC-MS and infrared spectrometry.

\section{Conclusions}

The combination of scanning thermal microscopy and localized thermal analysis presents a powerful new form of analytical microscopy, which is able to elucidate the organization and constitution of materials. The addition of a localized form of chemical analysis by pyrolysis-GC-MS to this technique provides an independent means of identification and which is essential in cases where there is no a priori knowledge of the specimen's makeup or there is unclear discrimination between phases. This combined approach presents the possibility of visualizing a specimen's structure, characterizing its thermal properties and analyzing its chemical composition.

\section{Acknowledgements}

DMP would like to thank the UK Engineering and Physical Sciences Research Council for financial support.

\section{References}

[1] D.M. Price, M. Reading, T.J. Lever, J. Therm. Anal. Cal. 56 (1999) 673.

[2] D.M. Price, M. Reading, A. Hammiche, H.M. Pollock, M.G. Branch, Thermochim. Acta 332 (1999) 143.

[3] D. Briggs, Surface Analysis of Polymers by XPS and Static SIMS, Cambridge University Press, Cambridge, 1998.

[4] T.R. Crompton, Practical Polymer Analysis, Plenum Press, New York, 1993, pp. 73-92 (Chapter 4).

[5] J. Chiu, in: J. Mitchell Jr. (Ed.), Applied Polymer Analysis and Characterization: Recent Developments in Techniques, Instrumentation, Problem Solving, Hanser, Munich, 1987, pp. 184-215.

[6] N. Grassie, G. Scott, Polymer Degradation and Stabilisation, Cambridge University Press, Cambridge 1985 (Chapter 2).

[7] W.C. McClennen, R.M. Buchanan, N.S. Arnold, J.P. Dworzanski, H.L.C. Meuzelaar, Anal. Chem. 65 (1993) 2819.

[8] J. Mullens, R. Carleer, G. Reggers, M. Ruysens, J. Yperman, L.C. Van Poucke, Bull. Soc. Chim. Belg. 101 (1992) 267.

[9] A. Hammiche, H.H. Pollock, M. Reading, M. Claybourn, P.H. Turner, K. Jewkes, Appl. Spectrosc. 53 (7) (1999) 810. 